\title{
Determining the Challenges Faced by Syrian Refugees Students at Jordanian Camps According to Their Perspective: A Case of Universities Role to Supporting
}

\author{
Luma Fakhir AbduRazak ${ }^{1}$, Reda Salamah AL Mawdieh ${ }^{2}$, Asaad Ali Karam ${ }^{3}$, Abdulsalam Yousef Aljaafreh ${ }^{1} \&$ \\ Mohammed Elias Al-Azzaw ${ }^{1}$ \\ ${ }^{1}$ Zarqa University- Faculty of Education, PhD., Jordan \\ ${ }^{2}$ Zarqa University- Faculty of Education-Dean of Education, PhD., Jordan \\ ${ }^{3}$ City University College of Ajman, HRM Department, PhD., UAE \\ Correspondence: Asaad Ali Karam, Dept. HRM, City University College of Ajman, Ajman, Sheikh Ammar Road, \\ Al Tallah 2 Ajman, UAE. E-mail: asaad.ali@uod.ac
}

Received: April 15, 2019

Accepted: July 29, 2019

Online Published: July 30, 2019

doi:10.5539/mas.v13n8p176

URL: https://doi.org/10.5539/mas.v13n8p176

\begin{abstract}
This study aimed to identify the most important challenges facing the Syrian refugee university students in Jordan camps, and the universities' role in supporting them from their perspective, by providing answers to the following questions: What are the challenges that facing the Syrian refugee university students in Jordanian camps from their perspective? And what kind of support could Jordanian universities provide for the Syrian refugee university students from their perspective? This study employs a quantitative and qualitative approach and intends to explore the challenges and opportunities for Syrian refugee students in Jordan. The results show that the large number of Syrian Refugee University Students at Jordanian camps present challenges for local communities in meeting the needs of both the refugees and the host universities. Refugees face multiple challenges in Jordan:(1) Financial shortcomings; (2) legal issues including lack of documentation and restrictive host country policies; (3) Psychological and Family challenges. Findings of the study add to the understanding of the vital role of higher education in improving living conditions and giving a sense of hope for the future. The study offers policy and program recommendations to decision- and policy-makers for the national and international communities, donors and other institutions with the overall goal to improve and guide further practice and research in supporting access to higher education.
\end{abstract}

Keywords: Syrian refugees, higher-education, student challenges

\section{Introduction}

In 2010, Syria underwent the Arab Spring through which the public claimed for more freedom. However, things became more complicated and the situation turned into a fierce war between the Syrian government and the forces opposing it. The scenario became even more complicated after some international allies and new regional forces interfered. After such as interference, the destructive and violent acts increased and towns were fully destroyed. That was done through using all kinds of ground, aircraft, and naval heavy weapons and missiles. In this war, the Syrian civilians fell as victims. For instance, hundreds of thousands of Syrian civilians were killed and millions of Syrian civilians were internally displaced. In addition, millions of Syrian civilians sought asylum at Europe. However, many of them died while attempting to reach Europe. For instance, many people drowned in the sea because they were using inflatable boats or pitiful ships.

Jordan hosts numerous Syrian refugees. To be specific, it hosts about 1265514 Syrian refugees. $22 \%$ of them are living in camps, whereas $78 \%$ of them are living in cities. 435578 Syrian refugees are living in Amman and 343479 Syrian refugees are living in Irbid. In addition, 207903 Syrian refugees are living in Mafraq and 175280 Syrian refugees are living in Zarqa. There are other Syrian refugees who are living in other Jordanian cities.

According to the statistics of the United Nations High Commissioner for Refugees (UNHCR), there are 736,396 refugees living in Jordan. Based to the latter statistics, Jordan is ranked second among countries in terms of the refugee-per-capital ratio. For instance, Jordan hosts (89) refugees per 1,000 inhabitants living in Jordan. As for the Syrian refugees only, 1 refugee out of 4 refugees sought asylum in Jordan. Jordan is the first country that 
provided Syrian camps with electricity. For instance, it provided Al-Za'tari refugee camp with electricity through Al-Azraq project. Through the latter project, the solar power is converted in an electrical power.

The Jordanian Ministry of Labor has issued 52,906 work licenses for Syrian refugees (UNHCR, 2017). However, there are other workers who work on a daily remuneration basis and do not need a work license. The number of the latter workers is much greater than the ones who are licensed.

Jordan and other international organizations have provided many facilities and services to Syrian refugees in camps. However, the ones who live in a camp can never have a normal life. For instance, there are many problems and challenges facing the Syrian refugees at camps, especially the Syrian refugee who seeks obtaining a university degree.

When a war is waged and various weapons are used to destroy things, many people flee the country seeking asylum. These people leave behind everything they have in order to survive. Most likely, those people have undergone terrifying conditions. Such conditions may include seeing their parents killed, arrested or tortured or shelling their homes. Such condition may include getting arrested or tortured. All these terrifying conditions have negative impacts on their psychological status. These conditions introduce new challenges that aren't easy to be overcome.

The review of some of the related studies that address refugee issues, showed that these studies shed a light on the refugees' needs, psychological situation and attitudes towards the hosting country. Such as Gordon's study (2017) who surveyed 27739 individuals living in South Africa, He concluded that the respondents have major concerns about refugees' issues and prefer living in isolation away from them. In addition, Pena (2017) surveyed several Mexican illegal immigrants who were deported from the United States of America. He interviewed (47) Mexican illegal immigrants who were deported from USA. He found that they were suffering from post-traumatic stress disorder. As for Bradley et al. (2017), they aimed to introduce durable solutions for the problems of the ones who were displaced involuntarily in Philippin. They concluded that those people suffer from post-traumatic stress disorder.

Kelly (2017) surveyed several people living at Feffernitz Displaced People's Camp. Those people were displaced involuntarily after the Austrian war under the authority of the British Military Government. He advises charitable groups to separate the process of making political decisions from humanitarian issues related to refugees.

A review of the study conducted by Thoresen (2017), aimed to explore the needs of refugee and asylum-seeking children living in precarious circumstances. The study conducted by (Eghdamian 2017). Aimed to explore the Syrian refugees' interaction with the local community in Jordan explained that most of the Syrian refugees interact with the local community. However, a few numbers of monitory do not interact with the local community in Jordan that was attributed to the difference in religion.

There are many studies that shed a light on the conditions of the Syrian refugees enrolled at the universities located in Western Europe. Such studies include the one conducted by (Dv, 2017) which bn shed a light on the activities carried out by the Syrian refugee students in Germany. The surveyed students were enrolled at the Free University of Berlin. The study was conducted in the aim of changing the negative image that Germans have about Syrian refugees. Hussain (2017) aimed to shed a light on the courses that promote the integration of Syrian refugees in the German community. The examined courses were the German language course (900 hours) and a course about Germany and its administrative divisions (100 hours).

Some of the studies were done in Jordan about the Syrian university refugee students, like Al-Hawamdeh and Elghaly (2017) on the higher education for Syrian refugees in Jordan, was a part of a broader regional study for the national and international communities and commissioned by UNESCO. The report presents the findings of an investigation that aims to identify major lines of action of Syrian refugees enrolled in higher education institutions in Jordan. The report employs a qualitative approach that intends to explore and understand the challenges and opportunities of Syrian refugee students to access higher education. Research shows that due to Jordan's financial difficulties, the government's attempts to revise clear and effective policies to accommodate for the influx of Syria refugee students to the higher education sector are limited. Similarly, the lack of communication and coordination between key stakeholders including tertiary sector institutions, international organizations and policy-makers, result in a significant gap in the understanding and implementing of these potential policies. Moreover, scholarship providers and international and local policy-makers are focusing more on the primary and secondary education sectors in Jordan.

A study by Dunmore (2017) about online study scheme gives refugee students a degree of hope in Azraq camp in Jordan. The course tutors and professors try to visit students in the camp at the start and end of term, in the first case to hold selection exams and introduce those selected to the course, and later to oversee an end-of-course workshop and final exam 
Based on the previous studies, it can be noticed that the present study aimed to shed a light on a new issue about Syrian university refugee students. This issue is represented in the challenges facing them in their study and life in general at Al-Za'tari refugee camp in Jordan.

\section{The Problems}

Every human being when he is displaced from his or her home and homeland, especially by force and war disasters, to another land or country, where he will live as a stranger, nearly without anything to eat, and no money to buy. The problem becomes more difficult with the family that have young children in different ages, as well as, the olds. These unlucky people, try their best to live, and hope the others will help them to do so. The youth who are at the age of high school and university, are the most anxious and have a fear of the future, if they cannot complete their study. They feel that they are lost, and this feeling makes them ready to do anything bad or dangerous, toward themselves, and the others. So the world society must help them to live survive and achieve some other main goals, such as teaching their sons and daughters, from elementary school till the university. This goal or dream of the refugees, cannot becomes real without an international aid. Even with this support, many problems and obstacles face will face the students, especially at the higher education, because some of the refugees' supporters believe that this level of study is not necessary as the elementary and secondary studies in the refugees' life. This type of believe and other problems, pose heavy challenges on the university refugee students.

The problem of the present study is represented in the following questions:

(1): include the following: perspective?

a) What are the challenges facing the Syrian refugee university students at Jordanian camps from their

b) What is the level of importance of challenges: high, moderate, or low?

c) Are there statistical differences among the general means of the three categories of the economic and financial, family, and psychological challenges?

(2): What kind of support could the Jordanian universities provide for the Syrian refugee university students at Jordanian camps from their perspective?

\section{Study Limitation}

The results of the present study can't be generalized. That is because the study is limited to its sample and instrument. The sample consists of Syrian refugee university students living at Al-Za'tari refugee camp in Jordan. The sampled students are distributed equally according to their gender (females and males). As for the study's instrument, it is represented in a questionnaire that was prepared for the study in 2017.

\section{Methodology}

Population: The study's population involves all the Syrian refugees who are enrolled in Jordanian universities in Al-Za'tari refugee camp.

Sample: The study's sample consists of (300) Syrian refugee university students living at Al-Za'tari refugee camp in Jordan half of them were females and the others males.

\subsection{Operational Definitions of the Terms}

1): Refugees: This term refers to the Syrians who fled Syria and sought asylum in Jordan due to the Syrian civil war.

2): Challenges: This term refers to the problems or obstacles that face Syrian refugee university students who live at Al-Za'tari refugee camp in Jordan

\subsection{Instrument}

In order to fulfill the study's goals, the researchers of the present study developed a questionnaire. The questionnaire - in its final form - consists from 20 items. These items deal with the challenges facing -Consist of: 1) Economic and financial challenges; 2) Family related challenges and 3) Psychological challenges- the Syrian refugee university students at Jordanian camps. Five multiple choice answers were provided for each item. The respondent shall put the sign $(\sqrt{ })$ in the box that represents his / her opinion. The respondent answer represents how important the challenge is, with a Likert-type scale in: (Strongly agree, agree, neutral, disagree, and strongly disagree). These alternatives were given the following scores respectively: $(5,4,3,2,1)$. Thus, the maximum value is 5 and the minimum value is 1 , with a total score ranging between (20-100). 


\subsection{The Instrument's Validity}

A jury of (5) specialists in education and psychology, who were members of a faculty of education judged the validity of the items to measure the university Syrian refugee students' challenges. The items that were approved by $(80 \%)$ of the jury members or more were accepted. All the items were accepted, with a modification in four of them.

\subsection{Reliability}

After checking the questionnaire's validity and distributing the questionnaire's to the students' sample, a sample of (40) students' answered questionnaires were chosen randomly and analyzed statistically, the reliability was (.84) by Cronbach's-Alpha coefficient internal consistency, as shown in table (1). Furthermore, the reliability of any given measurement refers to the extent to which it is a consistent measure of a concept, and Cronbach's alpha is one way of measuring the strength of that consistency, in general, the value should be more than $(0.7)$ it's usually good, hence, in the present study the score was $(0.814)$ this could be a very high degree of internal consistency (Karam, A. A. 2019).

Table 1. Reliability Statistics

\begin{tabular}{ccc}
\hline Cronbach's Alpha & Cronbach's Alpha Based on Standardized Items & N of Items \\
\hline .84 & .814 & 20 \\
\hline
\end{tabular}

\subsection{Criteria of Classifying the Means}

The means of the items are classified into high, moderate, and low means. Such a classification is based on the following criteria:

Low: (1-2.33)

Moderate: (2.34-3.67)

High: (3.68-5)

These criteria were set through the following method:

(The maximum value - the minimum value) / The number of required scores $=(5-1) / 3=1.33$

The latter value (1.33) was added to each value to set the three classification criteria.

The researchers of the present study also calculated the mean of the five rating points of the adopted scale $=$ $\frac{\text { The sum of the flve rating polnte }}{5}=\frac{1+2+8+4+6}{6}=3$

The cut-off points

The range of the cut-off point was calculated. This range is represented in the following range: $(3.68-5)$. In case the overall mean falls within the latter range, the challenges shall be considered very serious challenges jointly.

\section{Study Results}

First: The Results related to the first question:

The study's first question is represented in the following sub questions:

Q1):

A): What are the challenges that facing the Syrian refugee university students at Jordanian camps from their perspective?

The results showed that the challenges which facing the Syrian refugee university students are (20), distributed in three categories: the economic and financial with (5) challenges; the family with (8) challenges; the psychological with (7) challenges. Table (3) shows these challenges.

Q1):

B): Is the level of the importance of challenges: high, moderate, or low?

In order to provide an answer to this question, it needs to identify the general mean of the three types of challenges jointly.

It was found that the general mean of all the examined types of challenges is 4.25 which is equivalent to the degree of $85 \%$. With a general standard deviation of the three types of challenges which equal 0.64 . The general mean fall within the high range of $(5-3.68)$, which indicates that these challenges are very important.

Q1):

c): Are there statistical differences among the general means of the three categories of the: economic 
and financial, family, and psychological challenges?

Analysis of variance shows no statistical differences among the three general means of the categories of challenges: the economic and financial mean 4.56 with a standard deviation .06 ; the family mean 4.0 with a standard deviation .78; the psychological mean 4.50 with a standard deviation .60, as shown in table (2).

Table 2. Analysis of variance of the three challenges categories

\begin{tabular}{ccccc}
\hline Source of variance & Sum of Sqrs. & $d f$ & Mean sum of Sqrs. & F-ratio \\
\hline Between groups & 1.60 & 2.80 & $3.33^{*}$ & \\
Within groups (error) & 4.12 & 17.12 & & \\
\hline
\end{tabular}

* F-ratio at .05 with a df 2, 17 equal (6.11)

This result indicates that the three kinds of challenges: the economic and financial; the family; and the psychological have nearly the same high importance. It can be noticed that their mean values are close to each other and the differences between them are minor differences. All these values are considered high, and indicates that these challenges are very important and crucial challenges from the respondents' perspective.

As for the means of the single item, the item that deals with (the fear of being deported back to Syria) shows a mean of 4.9 which is the highest. The item that deals with (having worries about the future) shows a mean of 4.8. The latter mean is ranked second. The item that deals with (the insufficiency of the UN financial aid) shows a mean of 4.8, and ranked second. Table (2) below presents the mean of each item.

Table 3. The challenges which Syrian refugee students face and their means and standard deviations

\begin{tabular}{|c|c|c|c|}
\hline Item No. & The challenge & Mean & $\begin{array}{l}\text { Standard } \\
\text { deviation }\end{array}$ \\
\hline First & Economic and financial challenges & & \\
\hline 1 & Poverty & 4.5 & 0.42 \\
\hline 2 & $\begin{array}{c}\text { The unavailability of job opportunities in which I am allowed to } \\
\text { work after class and during holidays }\end{array}$ & 4.2 & 0.73 \\
\hline 3 & The insufficiency of the UN financial aid & 4.8 & 0.53 \\
\hline 4 & $\begin{array}{c}\text { The prices of goods and services are high relative to the family's } \\
\text { income }\end{array}$ & 4.6 & 0.64 \\
\hline \multirow[t]{2}{*}{5} & There isn't any income source in Syria anymore & 4.7 & 0.48 \\
\hline & Total of economic and financial challenges & 4.56 & 0.56 \\
\hline Second & Family related challenges & & \\
\hline 6 & $\begin{array}{l}\text { There are major family-related responsibilities that the students } \\
\text { must handle }\end{array}$ & 3.4 & 0.59 \\
\hline 7 & $\begin{array}{c}\text { The absence of the eldest family members due to migration or } \\
\text { death }\end{array}$ & 4.2 & 0.92 \\
\hline 8 & The small area of the dwelling & 4.6 & 0.76 \\
\hline 9 & Early marriage & 3.9 & 0.47 \\
\hline 10 & Family violence due to poor life conditions & 4.1 & 0.85 \\
\hline 11 & Divorce & 3.4 & 0.79 \\
\hline 12 & Having the family members scattered in different countries & 3.8 & 0.83 \\
\hline \multirow[t]{2}{*}{13} & $\begin{array}{l}\text { Difficulty to provide my needs as a university student by my } \\
\text { family. }\end{array}$ & 4.23 & 0.48 \\
\hline & Total of family related challenges & 3.95 & 0.78 \\
\hline Third & Psychological challenges & & \\
\hline 14 & Having worries about the future & 4.8 & 0.34 \\
\hline 15 & Depression & 4.7 & 0.56 \\
\hline 16 & $\begin{array}{l}\text { Feeling oppressed and believing that the international } \\
\text { community has given up the Syrian case }\end{array}$ & 4.5 & 0.78 \\
\hline 17 & Feeling isolated and alienated & 4.3 & 0.84 \\
\hline 18 & Fear of having a decline in academic performance & 4.4 & 0.45 \\
\hline 19 & Fear of being deported back to Syria & 4.9 & 0.58 \\
\hline \multirow[t]{3}{*}{20} & Worrying about the psychological health of the family members & 3.9 & 0.69 \\
\hline & Total of psychological challenges & 4.50 & 0.60 \\
\hline & Total & 4.34 & 0.64 \\
\hline
\end{tabular}


It can be noticed that the general mean of each type of challenge is above average. That indicates that each type of challenge is considered serious and crucial. The same applies to all the examined types of challenges jointly.

The general mean of the importance of the financial and economic challenges is 4.56 and got the first rank. The general mean of the seriousness of the psychological challenges is 4.5 and got the second rank. The general mean of the family-related challenge is 4.08 and got the third rank. These results showed that the financial and economic challenges are the most serious and crucial type of challenges, followed by psychological challenges and family-related challenges respectively...

In terms of economic and infrastructure development, the UAE is the fastest growing country in the Arab world and the student are playing a crucial role in the country's economic and social development, This in itself is part of the solution to contemporary economic challenges (Kitana \& Karam, 2017).

As for the means of the single item, the item that deals with (the fear of being deported back to Syria) shows a mean of 4.9 and was the highest. The item that deals with (having worries about the future) shows a mean of 4.8 and was ranked second. The item that deals with (the insufficiency of the UN financial aid) shows a mean of 4.8. The latter mean is also ranked second.

The items that deal with divorce and handling major family related responsibilities show a similar mean which is 3.4. The latter mean is considered the least mean. It can be noticed that the latter mean falls within the range of (2.34-3.67). That means that the seriousness of these challenges are considered moderate.

The results of the present study are in agreement with the results concluded by Dv (2017). The latter researcher found that Syrian refugees suffer from the negative stereotypical ideas that Germans have about them. For instance, many Germans think that Syrians are violent. In addition, the results of the present study are in agreement with the results concluded by (Pena, 2017). The latter researcher surveyed several Mexican illegal immigrants who were deported from the United States of America (USA). He found that the respondents suffer from post-traumatic stress disorder. The results of the present study are also in agreement with the results concluded by Bradley et al. (2017), they concluded that the ones who were displaced involuntarily in Philippines suffer from post-traumatic stress disorder.

As per Karam \& Kitana, (2018) a study which was conducted to the role of social media on human resource management, the study found there was a strong psychological effect, Through a testimonial to innovation and socialite construction, the study has indicated how authoritative and singular vigour may change while occurring in simulated environments concerning to HRM.

\subsection{Results Related to the Second Question}

Q2): What kind of support could Jordanian universities provide for the Syrian refugee university students at Jordanian camps from their perspective?

The content analysis method was used for analyzing the respondents' answers to the second question. This analysis was conducted in the aim of identifying the support that Jordanian universities could provide for Syrian refugee university students at Jordanian camps from their perspective. Such support shall enable those students to overcome the challenges they face.

After conducting the analysis, it was found that respondents believe that Jordanian universities must conduct diagnostic studies. They state that those studies must aim at exploring the psychological, health and family related problems that Syrian refugee university students at Jordanian camps suffer from. They also state that such studies must be conducted by Jordanian universities because they have human resources who have adequate expertise in the fields of medicine, psychiatry, counseling, and sociology.

In addition, respondents state that Jordanian universities must establish research centers that are specialized in asylum and immigration issues. Respondents also state that Jordanian universities must provide partial and full scholarships for Syrian refugee university students. They also state that Jordanian universities must provide Syrian refugee university students with courses about English languages and mathematics. Respondents also state that Syrian refugee university students must be provided with a job opportunity within the universities. Respondents also state that Jordanian universities must engage Syrian refugee university students in the university's activities and events.

\section{Recommendations}

In the light of the results, it can be recommend to meet the needs of the Syrian refugee university students in increasing the awareness of the importance of higher education for refugees, and facilitating better collaboration channels/methods with and among INGOs/ NGOs, conducting studies because they have human resources who 
have adequate expertise in the fields of medicine, psychiatry, counseling, and sociology, establishing research centers that are specialized in asylum and immigration issues, and providing partial and full scholarships for high achiever Syrian refugee university students.

\section{References}

Al-Hawamdeh, A. \& Elghaly, H. A. (2017). Higher education and Syrian refugee students: The case of Jordan. The Regional Conference on Higher Education in Crisis Situations, Sharm El-Sheikh-Egypt, 28-29, March, 2017.

Bradley,M., Sherwood, A., Rossi, L., Guiam, R. \& Mellicker, B. (2017). Researching the resolution of post-disaster displacement: Reflections from Haiti and the Philippines. Journal of Refugee Studies, 30(3), 363- 386.

Dunmore, Ch. (2017). Online study scheme gives refugee students a degree of hope. From UN High Commissioner for Refugees.

Eghdamian, K. (2017). Religious identity and experiences of displacement: an examination into the discursive representations of Syrian refugees and their effects on religious minorities living in Jordan. Journal of Refugee Studies, 30(3), 447-467.

Gordon, G. (2017). A desire for isolation? Mass public attitudes in South Africa toward immigration levels. Journal of Immigrant \& Refugee Studies, 15(1). https://doi.org/10.1080/15562948.2016.1151096

Hussain, M. A-D. (2017). Syrian students seek to ease prejudices between refugees and Germans. www.hnfomigrants,net/ar/post/6167/20111/2017.

Karam, A. A. (2019). The Impact of Training and Development on Different Cultural Employees Performance through Interaction Employees Motivation in Erbil Public and Private Banks. Mediterranean Journal of Social Sciences, 10(1), 193. https://doi.org/10.2478/mjss-2019-0017

Karam, A. A. \& Kitana, A. F. (2018). The Impact of Social Media on Human Resource Management Scope Activities in Al-Futtaim and Al-Etihad Group UAE. International Business Research, 11(12), 145-156. https://doi.org/10.5539/ibr.v11n12p145

Kelly, L. (2017). Humanitarian sentiment and forced repatriation: The administration of Hungarians in a post-war displaced persons camp. Journal of Refugee Studies, 30(3), 387- 406.

Kitana, A. \& Karam, A. A. (2017). The relationship between work environment into women's career development and job satisfaction in the United Arab Emirates: A large scale sampling. International Journal of Business and Management Invention, 6, 22-28.

Peña, J. M., Garcini, L. M., Gutierrez, A. P., Ulibarri, M. D. \& Klonoff, E. A. (2017). Traumatic Events and Symptoms Among Mexican Deportees in a Border Community. Journal of Immigrant \& Refugee Studies, 15(1), 36-52. https://doi.org/10.1080/15562948.2016.1158341

Thoresen, P, Fielding, A, Gillieatt, S \& Thoresen, S. H. (2017). Identifying the needs of refugee and asylum-seeking children in Thailand: A focus on the perspectives of children. Journal of Refugee Studies, 30(3), 426-446.

UNHCR Jordan. (2017). Factssheet.Reliefweb https://reliefweb.

\section{Copyrights}

Copyright for this article is retained by the author(s), with first publication rights granted to the journal.

This is an open-access article distributed under the terms and conditions of the Creative Commons Attribution license (http://creativecommons.org/licenses/by/4.0/). 